\title{
Acute Respiratory Failure during Pediatric Anesthesia: Atelectasis and Hypertensive Pneumothorax: Case Report
}

\author{
Joel Massari Rezende, TSA 1, Bruno Ricciardi Silveira ${ }^{2}$
}

Summary: Rezende JM, Silveira BR - Acute Respiratory Failure during Pediatric Anesthesia: Atelectasis and Hypertensive Pneumothorax: Case Report.

Background and objectives: The main anesthesiologist's task is to ensure appropriate oxygenation of patient. The objective of this report is to describe both diagnosis and behavior in case of acute respiratory failure during anesthesia, with educational purposes.

Case report: Three-year-old child underwent anesthesia for urologic surgery presented respiratory failure by bronchial obstruction by secretion, evolving to atelectasis and hypertensive pneumothorax. We present the evolution of the case and applied treatment means, emphasizing the urgency and drainage technique in hypertensive pneumothorax.

Conclusions: The anesthesiologist's attention to early diagnosis of respiratory complications and knowledge of priority measures in each moment may prevent serious adverse effects.

Keywords: Respiratory Insufficiency; Child, Hospitalized; Pulmonary Atelectasis.

\section{INTRODUCTION}

During general anesthesia the respiratory function can be optimized by, eliminating mouth, pharynx and larynx obstructions with intubation and controlling many parameters, such as composition of inspired mixture, tidal volume and rate. On the other hand, natural regulation and defense mechanisms are neutralized, and it becomes the physician's responsibility to keep respiratory function within physiologic conditions, with the assistance of monitors and respirators. Nevertheless, pediatric anesthesiologists, understanding all the internal logistical problems to operate a child, tend to be permissive with the presence of recent upper airway infections.

This report describes respiratory complications initially originated by undetected presence of secretion in the lungs (likely consequence of recent infection), that led to hypertensive pneumothorax and acute respiratory failure. Its description may be useful to clarify some physiopathological mechanisms and draw attention to serious emergence of hypertensive pneumothorax and its treatment.

Received from Hospital Infantil Darcy Vargas, Brazil.

1. Instructor of CET of Hospital do Servidor Público Estadual de São Paulo Francisco Morato de Oliveira; Anesthesiologist of Hospital Infantil Darcy Vargas

2. ME-3 Resident Physician of CET of Hospital do Servidor Público Estadual de São Paulo Francisco Morato de Oliveira

Submitted on: November 28, 2009.

Approved on: May 19, 2011.

Correspondence to:

Dr. Joel Massari Rezende

Avenida Conselheiro Rodrigues Alves, 999, apto 71

Vila Mariana

04014012 - São Paulo. SP, Brazil

E-mail: joelrezende@terra.com.br

\section{CASE REPORT}

Three-year-old patient with the following case history: intrauterine diagnosis of hydronephrosis; persistence of urogenital sinus; after birth it evolved with repeated urinary tract infections, underwent left ureterostomy, right nephrectomy, followed by a ureteral reimplant and stoma closure, remained with repeated urinary infections and then this surgery was suggested to achieve a Mitrofanoff derivation. This procedure consists of detaching cecal appendix with its meso and uses it to perform a conduit between bladder and umbilical scar; opening by umbilical scar constitutes a stoma that ensures a good continence, being easy to deplete through a tube introduced in a painless way - the patient himself becomes used to do it some times a day.

In the preoperative evaluation, no evidences of pulmonary infection or secretion were observed and laboratory exams were normal.

A pre-anesthetic medication was given with oral administration of midazolam $0,5 \mathrm{mg} \cdot \mathrm{kg}^{-1}$. Inhaling induction was done with nitrous oxide and sevoflurane; after venous puncture, propofol, fentanyl and atracurium were administered; intubation was done with endotracheal tube number five, without cuff; prophylactic antibiotic therapy was performed with the administration of cefalotin. In auscultation after intubation, a reduction of respiratory noise in left hemithorax was observed; the endotracheal tube was more proximally repositioned, which seemed to solve the problem. Volume mechanical ventilation (tidal volume of $140 \mathrm{~mL}$ ), maximum inspiratory pressure of $40 \mathrm{~cm}$ of water, with air (1 L.min $\left.{ }^{-1}\right)$, oxygen (1 L.min $\left.{ }^{-1}\right)$, and sevoflurane mixture (anesthetic machine Drager Primus) were instituted. Sacral epidural block was associated. The surgery continued for approximately 1 hour, when a decrease in oxy- 
gen saturation was observed, with $\mathrm{SpO}_{2}$ dropping progressively to $90 \%$, with normal capnography curve and $\mathrm{ETCO}_{2}$ near $30 \mathrm{mmHg}$, suggesting moderate hyperventilation.

The position of the tube and placement of the oximetry sensor were checked and both were adequate. Manual ventilation was started with Mapleson D system (Baraka), without improvement; $\mathrm{FIO}_{2}$ was increased to $100 \%$; aspiration through the light of the endotracheal tube did not produce significative quantity of secretion; the tube was exchanged for another one number five without cuff (the removed tube had a moderate quantity of secretion without significative decrease of internal light). At that moment, auscultation showed absence of respiratory noise in left hemithorax and sibilancy in the right one. A short time after starting manual ventilation, saturation dropped quickly $\mathrm{SpO}_{2}$ registering 40\%, and $\mathrm{ETCO}_{2}$ near $30 \mathrm{mmHg}$.

As the patient was still intubated and ventilated with $100 \%$ oxygen, there was a suspicion of hypertensive pneumothorax in the left side that would be interfering with venous return, cardiac function and right lung function itself, by distortion of mediastinal structures - which explained the seriousness of this case. The surgical sheets were partially distanced, taking caution to protect the surgery site. The fifth left intercostal space (identified by the height of nipple) was punctured with venous catheter number 20 between the anterior and medium axillary line, touching the upper edge of sixth rib to avoid vascular-nervous structures. It was then connected to a catheter which the other tip dipped in saline solution, inside a kidney basin. There were noticed bubbles and fast saturation improvement for values between $85 \%$ and $90 \%$, keeping pulmonary ventilation by Baraka.

There was no saturation rise for expected values, near $100 \%$; there was no significative increase of respiratory noise in left hemithorax. A clinical improvement was verified after drainage through the catheter and a thoracic drain was placed at the puncture site, with water seal ${ }^{1-3}$.

After the critical moment, thorax X-ray was performed. The $X$-ray showed opacification in left hemithorax (left lung atelectasis) and right lung hyperinsuflation; the pneumothorax image was not obtained (hyper-transparency of left hemithorax, with respective lung collapsed adjacent to hilum), as drainage was already done. A re-expanded left lung was expected to be observed, but the appearance was of persistent atelectasis despite thorax drainage (Figure 1).

Externally, the patient's thorax appeared a volume increase (at the expense of right lung hyperexpansion). It was suspected there was a complete obstruction of the left bronchus due to mucus plug. Aspiration through interior of tracheal cannula did not produce discernible volume of secretion, maybe because the aspiration cannula that passed through the tube's light necessarily had a limited caliber and lateral orifices to prevent injury of bronchial mucosa. Thus, it was decided to remove the tracheal cannula and aspire directly through the trachea with an aspiration tube as accurate as possible, with distal extremity sectioned in right angle to maximize its efficiency and then intubate again.

While this maneuver was being prepared, thoracic compressions were performed, trying to somehow imitate the

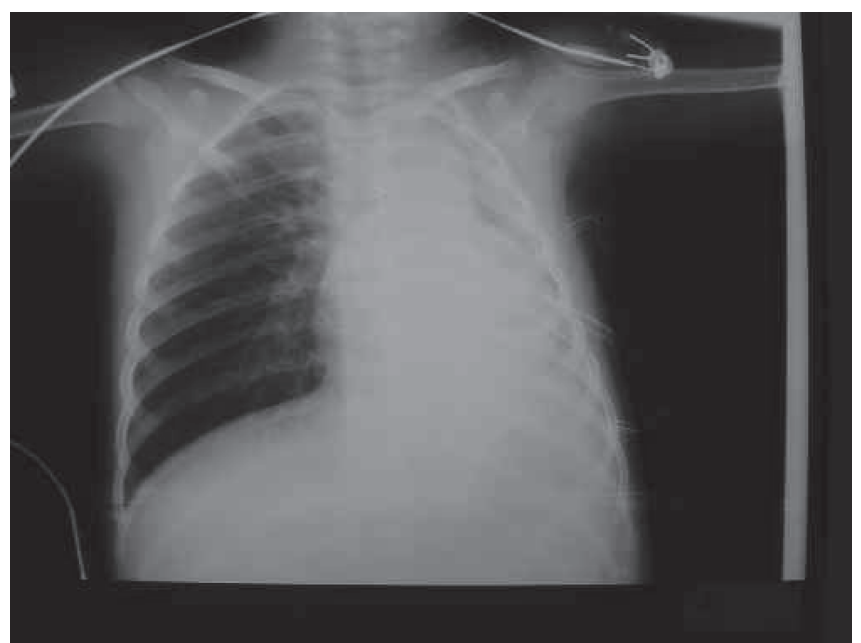

Figure 1 - X-Ray after Pleural Drainage in $5^{\text {th }}$ Left Intercostal Space. Hyper expanded right lung; atelectasis (collapsed left lung). It was not possible to radiologically register hypertensive pneumothorax, whose diagnosis was solely based on clinical criteria.

effect of cough to eliminate secretions. After a few compressions, saturation quickly increased to $98 \%$, remaining in this level. The trachea aspiration was then calmly performed and produced only a moderate quantity of secretion. The situation then stabilized and it was possible to keep anesthesia within normal parameters, reducing $\mathrm{FIO}_{2}$ to $50 \%$. Another thorax Xray was performed (Figure 2 ), in which it was observed a reexpansion of left lung (with atelectasis residual area).

The surgery was concluded. Then, the patient was sedated, intubated and sent to ICU with $95 \%$ to $96 \%$ saturation with $50 \%$ oxygen, spontaneous breath, alveolar noise bilaterally normal, without adventitious noise; 150 bpm tachycardia.

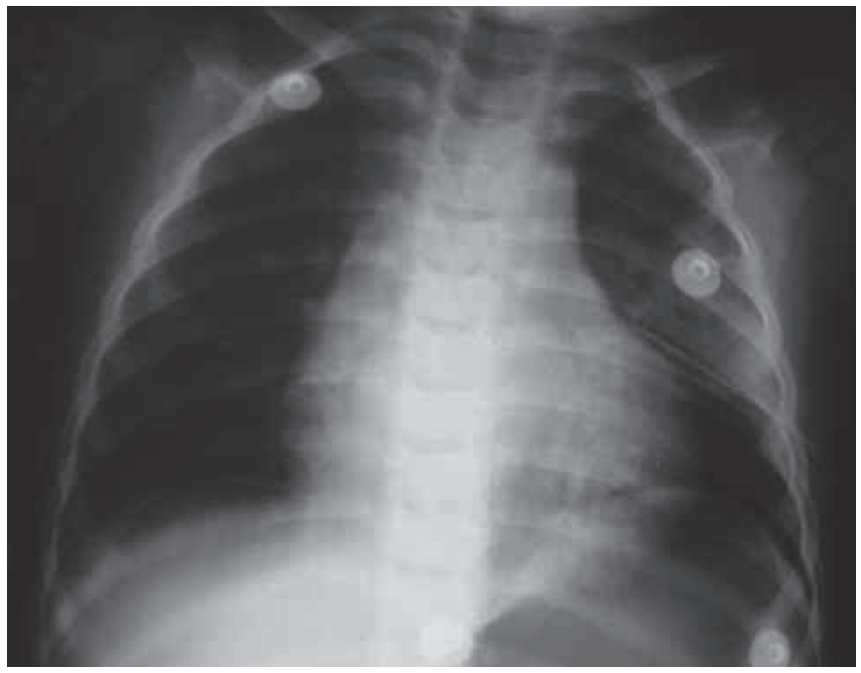

Figure 2 - X-Ray after Thoracic Compressions and Direct Tracheal Aspiration. It shows re-expansion of left lung, with residual atelectasis areas. Distended stomach by application of high ventilation pressure during serious desaturation, using intubation tube without cuff. 
After approximately 1 hour, having reduced the heart rate, the patient was extubated and kept with $\mathrm{O}_{2} 1$ L.min ${ }^{-1}$ catheter, breathing comfortably. Gasometry was performed, which showed the following results:

$$
\begin{aligned}
& \mathrm{pH}=7.4 \\
& \mathrm{pO}_{2}=90.1 \mathrm{mmHg} \\
& \mathrm{pCO}_{2}=35.3 \mathrm{mmHg} \\
& \mathrm{HCO}_{3}=22.1 \mathrm{mmol} . \mathrm{L}^{-1} \\
& \mathrm{BE}=-1.6 \\
& \mathrm{TCO}_{2}=23.1 \mathrm{mmol} . \mathrm{L}^{-1} \\
& \mathrm{SO}_{2}=97 \%
\end{aligned}
$$

Antibiotic therapy with amikacin, ampicillin and metronidazole was performed. The patient was transfered to the ward on the following day. The thorax drainage was removed on the third postoperative day, and the patient was discharged.

\section{DISCUSSION}

Even though it has not been possible to document the event with X-ray, the occurrence of hypertensive pneumothorax, with deviation of mediastinal structures and interference with cardiac and right lung function, seems to be the only possible explanation to fast clinical deterioration, with serious respiratory failure $\left(\mathrm{SpO}_{2}=40 \%\right)$ of intubated patient and ventilated with pure oxygen.

Hypertensive pneumothorax in anesthesia may occur by respirator malfunction ${ }^{4-6}$ - and it seems this was not the case - when using a Baraka device. It may be a consequence of an accidental increase of flow or exit orifice obstruction. In surgery to correct gastroesophageal reflux through video, passage of $\mathrm{CO}_{2}$ used in abdominal insufflation to thorax may occur through own diaphragmatic hiatus ${ }^{7,8}$. There may also be other causes like punctures to central access or upper limb block in cervical or thoracic region ${ }^{9}$, iatrogenic injuries in interventions on diaphragm ${ }^{10}$ or thoracic organs ${ }^{11-13}$ or penetrating wounds communicating with thorax ${ }^{14}$.

Formerly, it was recommended that the respirator was pressure cycled in low weight children. Even nowadays, some respirators only "accept" the pressure ventilation mode in case of patients weighting below $10 \mathrm{~kg}$. Others accept volume cycled, but establishing a limit value of pressure. In this case, the limit was $40 \mathrm{~cm}$ of water, a perfectly safe value for a healthy lung. It is possible that obstruction of left bronchus by presence of secretion had caused absorption of alveoli oxygen in this lung, not allowing the entrance of fresh gases, causing atelectasis zones ${ }^{15}$, and leading to progressive saturation drop until the observed value around $90 \%$. Capnography showed values around $30 \mathrm{mmHg}$, suggesting hyperventilation. Oxygen transport and consumption work with much more critical limits than $\mathrm{CO}_{2}$ elimination, so that a single working lung during anesthesia can keep low $\mathrm{ETCO}_{2}$, but can hardly keep saturation above $95 \%$, when $\mathrm{FIO}_{2}$ is of the order of 0.6 or less.
It is possible that when passing to manual ventilation, the passage of oxygen was forced to the left lung through the increase of insufflation pressure, stimulating a valvular mechanisn through accumulated secretion.

This increased insufflation, operating over a partially atelectasis lung, would lead to disruption in any segment and consequently to hypertensive pneumothorax, provoking collapse of all left lung. Consequently, the right lung function was also impaired by limitation of its expansion, distorting mediastinum structures, interfering with venous return and cardiac function - which caused the dramatic saturation drop to $40 \%$.

The acute and serious respiratory failure required immediate depletion of pneumothorax through puncture, even before radiologic evidence. In this case, puncture was made by venous catheter number 20 , using equipment and saline solution inside a kidney basin as water seal - which enabled to overcome the situation of very serious respiratory failure. The described technique is simple and safe and must be memorized by every anesthesiologist in case they have to handle a similar situation.

When there is a monopulmonary ventilation in healthy lung, with $100 \%$ oxygen, it is possible to keep normal saturation. In this case, after pneumothorax drainage, it was only possible to reach $85 \%$ to $90 \%$, probably due to existence of residual atelectasis areas, partially caused by obstruction of bronchi due to mucus plug ${ }^{16}$. The aspiration through tracheal cannula limited tube's caliber and did not enable efficient removal of secretion ${ }^{17}$. Probably, thoracic compressions worked in a similar way to cough action, dislocating obstruction of bronchi and facilitating re-expansion of atelectasis zones, which led to fast oxygenation normalization. Maybe they had operated partially in a similar way to Heimlich maneuver. We remind that this maneuver was suggested to help people who suffered respiratory obstruction through food (or another foreign body) and consists basically in compress the thorax base to dislocate food portion of the respiratory tree.

The sibilancy heard in hyperinsufflated right lung would probably be caused by distortions in bronchial tree consequent to the dislocation of mediastinal structures ${ }^{18}$.

\section{CONCLUSION}

There is no consensus on performing anesthesia or not in a child with upper airway infections: naturally, urgent surgeries are performed and optional ones are usually suspended in the presence of recent upper airway infections. But, taking into consideration that a normal child develops from three to eight episodes of upper airway infections each year and that bronchial hyperreactivity period is from six to eight weeks, it is hard to rigorously respect this period. Since studies do not report great morbidity in children with medium-intensity infection, we tend to avoid suspending surgeries whenever possible ${ }^{19}$.

Nowadays there are excellent mechanical ventilators and monitors to ventilation parameters: $\mathrm{SpO}_{2}$, capnography, pressure curves and tidal volume. Upon constant supervision it is possible to early diagnose any unexpected event, 
preventing or limiting hypoxia episodes - which is the main anesthesiologist's task.

When it is not possible to immediately diagnose the cause of a ventilation disorder, it is a practical measure to ventilate with Baraka connected to a pure oxygen source to "come back to basic" and gain time to solve the problem, taking care to avoid hyper pressure by accidental increase of flow, exit orifice obstruction or application of too much strength with hands.

A serious and sudden respiratory failure in intubated patient, with difficulty to pulmonary expansion and disappearance of respiratory noise in one hemithorax (or both) must immediately raise suspicion of hypertensive pneumothorax.
It is a serious emergency and an immediate thoracic puncture according to described technique should be considered in order to relieve tension and enable pulmonary re-expansion, even before radiological evidence (therefore it was not possible to document this fase in this case).

The attempt to solve a respiratory failure during anesthesia by thoracic compression maneuvers would seem inappropriate when the patient is intubated and oxygenated by insufflation directly in lungs. But, in this case, it seems to have been useful in re-expansion of atelectasis areas and removal of secretion held in respiratory tree, working as a cough mechanism or Heimlich maneuver (to obtain more data on this technique, access www.heimlichinstitute.org). 


\section{REFERENCIAS / REFERENCES}

1. Sharma A, Jindal $\mathrm{P}$ - Principles of diagnosis and management of traumatic pneumothorax. J Emerg Trauma Shock, 2008;1:34-41.

2. Bacon AK, Paix AD, Williamson RK et al. - Crisis management during anaesthesia: pneumothorax. Qual Saf Health Care, 2005;14:e18.

3. Wax DB, Leibowitz AB - Radiologic assessment of potential sites for needle decompression of a tension pneumothorax. Anesth Analg, 2007;105:5:13851388 .

4. Zugliani AH, Claro F, Mega ACC et al. - Barotrauma pulmonar no intra-operatório de procedimento cirúrgico oftalmológico. Relato de caso. Rev Bras Anestesiol, 2008;58:1:63-68.

5. Aguiar JrA - Pneumotórax bilateral em anestesia. Relato de um caso. (Carta ao Editor). Rev Bras Anestesiol, 1994;44(2):159-160.

6. Anagnostou JM, Hults SL, Moorty SS - PEEP valve barotrauma (Letter to Editor). Anesth Analg, 1990;70:674-675.

7. Posso IP, Awade R, Posso JP et al. - Pneumotórax hipertensivo durante videolaparoscopia para correção de hérnia do hiato esofagiano. Relato de dois casos. Rev Bras Anestesiol, 1998:48:3:198-201.

8. Videira RLR - Pneumotórax hipertensivo durante videolaparoscopia para correção de hérnia do hiato esofagiano. Relato de dois casos (Carta ao Editor). Rev Bras Anestesiol, 1998:48(5):443.

9. Basile Filho A, Capone Neto A, Araújo OC et al. - Pneumotórax tardio: uma complicação do cateterismo da veia subclávia (Carta ao Editor). Rev Bras Anestesiol, 1998;38:223-224.

10. Diaz JH - Tension pneumoperitoneum-pneumotorax during repair of congenital diaphragmatic hérnia. Anesth Analg, 1987;66:577-580.

11. Bessa Junior RC, Jorge JC, Eisenberg AF et al. - Ruptura brônquica após intubação com tubo de duplo lúmen. Relato de Caso. Rev Bras Anestesiol, 2005;55(6):660-664.

12. Silva RA, Braz LG, Ferrari $\mathrm{F}$ et al. - Pneumotórax hipertensivo secundário à perfuração esofágica. Sao Paulo Med J 2005;123(supl.spe):49.

13. Sushil K, Walker R - Bougie-related tension pneumothorax in a neonate. Pediatr Anesth, 2009;19:800-814.

14. Mega ACC, Encinas JMM, Blanco NP et al. - Pneumotórax hipertensivo na sala de recuperação pós-anestésica. Relato de caso. Rev Bras Anestesiol, 2004;54(5):681-686.

15. Malbouisson LMS, Humberto F, Rodrigues RR et al. - Atelectasias diramte anestesia: fisiopatologia e tratamento. Rev Bras Anestsiol, 2008;58(1):73-83.

16. Bould MD, Gothard JWW - Sudden hypoxia during anesthesia in a patient with Kartagener's syndrome. Pediatr Anesth, 2006;16:977-980.

17. Bodenham AR - Removal of obstructing blood clot from the lower airway: an alternative suction technique (Case report). Anaesthesia, 2002;57:40-43.

18. Samuel J, Schwartz S - Tension pneumothorax during dental anesthesia. Anesth Analg, 1988;67:1187-1188.

19. Módolo NSP - IVAS e anestesia: deve-se adiar a cirurgia? Atualização em Anestesiologia Volume VI. Editores Auler Junior JOC, Iwata NM, Pereira RIC - São Paulo. Office Editora, 2001, pp 13-25. 